\title{
Effects of Acupuncture on Th1, Th2 Cytokines in Rats of Implantation Failure
}

\author{
Juan Gui, Fan Xiong, Jing Li, and Guangying Huang \\ Institute of Integrated Traditional Chinese and Western Medicine, Tongji Hospital, Tongji Medical College, \\ Huazhong University of Science and Technology, Wuhan, Hubei 430030, China \\ Correspondence should be addressed to Guangying Huang, gyhuang@tjh.tjmu.edu.cn
}

Received 2 August 2011; Accepted 15 September 2011

Academic Editor: Gerhard Litscher

Copyright ( 2012 Juan Gui et al. This is an open access article distributed under the Creative Commons Attribution License, which permits unrestricted use, distribution, and reproduction in any medium, provided the original work is properly cited.

The aim is to explore the effect of acupuncture on Th1, Th2 cytokines in rats of implantation failure. Early pregnant rats were randomized into normal group $(\mathrm{N})$, implantation failure group $(\mathrm{M})$, acupuncture group $(\mathrm{A})$, progestin group $(\mathrm{H})$. The model was established with mifepristone. Samples of serum, endometrium were collected on Day 5, 6 and 8 of pregnancy. Compared with group $\mathrm{M}$, the number of embryos was significantly higher in groups $\mathrm{N}$, A and $\mathrm{H}$; IL-1 $\beta$, IL-2 protein in serum and endometrium were significantly lower in groups N, A and H, while IL-4, IL-10 were significantly higher in groups N, A and H; the endometrial IL-2, IL-4 mRNA were significantly lower in groups N, A and H, while IL-1 $\beta$, IL-10 mRNA were significantly higher in groups N, $\mathrm{A}$ and $\mathrm{H}$. Acupuncture could improve the poor receptive state of endometrium due to mifepristone by promoting Th2 cytokines secretion and inhibiting Th1 cytokines to improve blastocyst implantation.

\section{Introduction}

In recent years, the assisted reproductive technology has been greatly improved, but the success rate is still not high. The primary reason is blastocyst implantation failure. Implantation is one of the most important procedures in reproduction and the key for the success of pregnancy. In the process of blastocyst implantation, in order to adapt to the blastocyst adhesion, intrusive, growth, and development, the endometrium suffers complex changes including cell proliferation, differentiation, migration, and apoptosis. Various molecules are participating in this process. Thus, the crosstalk between the active blastocyst and receptive uterus is essential to implantation [1]. It is crucial to take timely modifications in the endometrium to become receptive to the developing embryo for successful implantation. [2]. The human endometrium becomes receptive to the embryo only for a limited period during the luteal phase of the menstrual cycle, under the influence of steroid hormones and paracrine factors originating from endometrial cells and the embryo [3]. Impaired endometrial receptivity is considered to be a major limiting factor for the establishment of pregnancy [4]. The regulation of endometrial changes is not exclusively by ovarian hormones, the immune system has been implicated in normal endometrial function, similar to processes taking place during inflammatory and reparative path. Thus, cytokines and immune cells play a major role in endometrial tissue regeneration, growth, differentiation, and shedding throughout the normal menstrual cycle and in remodelling during embryonic implantation and growth [5-7].

Cytokines play a critical role in pregnancy, particularly in the early stages during blastocyst implantation and placental development [8-13]. For some years, a prevalent theory has been that predominant production of so-called $\mathrm{T}$ helper type 2 (Th2) cytokines such as interleukin (IL)-4 and IL10 was characteristic of normal implantation and pregnancy, whereas in miscarriage, and recurrent miscarriage there was a predominant production of Thl cytokines such as IL-1 and IL-2 [14]. Therefore in the process of location, adhesion, and penetration, the endometrium not only has the morphologic changes but also has alteration in the expression of cytokines.

Repeated failures of in vitro fertilization and embryo transfer (IVF-ET) bring huge economic and psychological burden to infertility patients, therefore, we are expecting an economic and effective method to ameliorate implantation. A research has shown that acupuncture on the day of ET 
significantly improves the reproductive outcome of IVF, compared with no acupuncture [15]. Acupuncture seems to be a useful tool for improving pregnancy rate after assisted reproduction therapy [16]. Previous researches have proven that acupuncture treatment is effective for blastocyst implantation obstacle, but the mechanism is still not clear, so the aim of the experiment is to explore the possible way that acupuncture improves implantation and to provide more supports for rationale.

\section{Materials and Methods}

2.1. Animals and Grouping. Virgin, 10-week-old, weight $210 \sim 230 \mathrm{~g}$ female Wistar rats $(n=90)$ and reproductive adult male Wistar rats $(n=40)$, weight $250 \sim 300 \mathrm{~g}$, SPF grade were provided by the CDC of Hubei province (the animal certificate SCXK no. 2008-0005) and fed in the barrier system according to the institutional guidelines established by the Animal Care and Use Committee of Tongji Medical College, Huazhong University of Science and Technology. After adaptive feeding for 5 days, female rats were mated with male rats at $6 \mathrm{PM}$ with the scale of $2: 1$ and checked the vaginal smear at $8 \mathrm{AM}$ the next day $(\mathrm{D} 1=$ sperm on the vaginal smear detection). The pregnant rats were randomized into normal group $(N)$, implantation failure group $(M)$, acupuncture treatment group (A), and progestin treatment group $(\mathrm{H})$, with 18 rats in each group. Then, the 18 rats were equally randomized into D5 group $(n=6)$, D6 group $(n=6)$, D8 group $(n=6)$ according to the time of sampling.

2.2. Reagent and Main Devices. The mifepristone tablets (Beijing Zizhu Pharmaceutical Co., Ltd. China) and progestin (Zhejiang Xianju Pharmaceutical Co., Ltd. China) were provided by Tongji Hospital. DAB coloring reagent kit used for immunohistochemistry was product of Beijing Zhongshan Biotech Co., Ltd. China. Tissue protein extraction (AR0101-100) and BCA protein assay kits (AR0146) were purchased from Wuhan BOSTER Company, China. Cocktail protease inhibitor was purchased from Wuhan Gugeshengwu Technology Co., Ltd. China. Rat IL-1 $\beta$, IL2 , IL-4, and IL-10 enzyme-linked immunosorbent assay (ELISA) kits were purchased from Beijing NeoBioscience Technology Co., Ltd. China. The total RNA extract reagent (Trizol), PrimeScript RT reagent Kit Perfect Real Time (TaKaRa Code: DRR037A), and SYBR Premix Ex Taq (TaKaRa Code: DRR041) were purchased from TaKaRa Biotechnology (Dalian) Co., Ltd. Dalian, China. Rabbit polyclonal to IL-1 beta (ab9787), IL-2 (ab25104), IL-4 (ab9811), and IL-10 (ab9969) was purchased from Abcam Company, USA. Goat or rabbit anti-rat Actin polyclonal antibody (sc1616R) was purchased from Santa Cruz Biotechnology, Inc. California, USA. DyLight 800-Labeled Antibody To Rabbit $\operatorname{IgG}(\mathrm{H}+\mathrm{L})$ (Cat. No 072-07-15-06) was purchased from KPL, Inc. Maryland, USA. HRP-Goat anti-Rabbit IgG (H + L) Conjugate (Cat. No. ANT011) was purchased from AntGene Biotech Co., Ltd. China. Nucleic Acid/Protein Analyzer (DU730, BECKMAN COULTER, Inc., Fullerton, California, USA); Mastercycler gradient PCR apparatus
(Eppendorf Company, Germany); Canon Micro-imaging System (Canon 350 D, Japan); Applied Biosystems StepOne Real-Time PCR System (Applied Biosystems, California, USA); Microplate reader (BioTek Synergy2, Vermote, USA); Near infrared double-color laser imaging system (Odyssey LI-COR Inc, USA).

2.3. Modeling and Treatment. The mifepristone tablet was dissolved in an appropriate amount of edible sesame oil after tripsis to produce $2 \mathrm{mg} / \mathrm{mL}$ mifepristone solution. The rats in groups $\mathrm{M}, \mathrm{A}$, and $\mathrm{H}$ were given mifepristone solution at $5.5 \mathrm{mg} / \mathrm{kg}$ by neck subcutaneous injection on D1 at 9 $\mathrm{AM}$, while group $\mathrm{N}$ were injected with corresponding sesame oil. Group A started acupuncture treatment which selected bilateral "Housanli" (ST 36) and "Sanyinjiao" (SP 6) as the acupoints [17] from D1 at $3 \mathrm{PM}$ and the rats were fixed by self-made cloth bags. Acupuncture methods: continuous $25 \mathrm{~min}$ per day, rolling the needle every $5 \mathrm{~min}$, and treatment for 5-8 days by the same investigator for all the rats in group A. Group N and M were fixed for $25 \mathrm{~min}$ at daily $3 \mathrm{PM}$ for 58 days. Group $\mathrm{H}$ began progestin treatment $(40 \mathrm{mg} / \mathrm{kg} / \mathrm{day}$, im) from D1 for 5-8 days.

2.4. Sampling. The rats were narcotized with $1 \%$ pentabarbital sodium by intraperitoneal injection at $4 \mathrm{PM}$ on D5, D6, and D8 for each group. Uterus was taken out by laparotomy and flushed with normal saline. Part of the uterus was fixed in $4 \%$ paraformaldehyde solution for paraffin embedding, while other part was preserved in $-80^{\circ} \mathrm{C}$ refrigerator for future use. Blood was drawn from aorta abdominalis. After centrifuging at $3000 \mathrm{r} / \mathrm{min}$ for $20 \mathrm{~min}$, the serum was collected and stored in a $-80^{\circ} \mathrm{C}$ refrigerator.

2.5. ELISA for $I L-1 \beta, I L-2, I L-4$, and IL-10 Protein Expression in Serum and Endometrium. A quantitative sandwich enzyme immunoassay technique was used in accordance with the manufacturer's protocol. The sensitivity of the ELISA kits was $15 \mathrm{pg} / \mathrm{mL}$. None of the samples examined had a cytokine level $>2000 \mathrm{pg} / \mathrm{ml}$. The inter-assay and intra-assay coefficients of variation of the ELISA kits were less than $9 \%$.

2.6. Immunohistochemistry for Endometrial $I L-1 \beta, I L-2$, and IL-4 Protein Detection. The paraffin slides were kept in oven at $60^{\circ} \mathrm{C}$ for 1 hour. Then, the sections were deparaffinized in xylene and rehydrated through grades of ethanol in distilled water, rinsed with PBS three times ( 5 min each). After that, antigens were retrieved by microwave processing with $10 \mathrm{mM} \mathrm{Na}$-citrate $(\mathrm{pH} 6.0)$ at $92-98^{\circ} \mathrm{C}$ for $20 \mathrm{~min}$. After natural cooling to room temperature, rinsed in PBS, endogenous peroxidase activity was quenched with $3 \% \mathrm{H}_{2} \mathrm{O}_{2}$ in PBS for $10 \mathrm{~min}$, followed by washing in PBS, three times, 5 min each. Sections were blocked with $1 \%$ Bovine Serum Albumin (BSA) for $30 \mathrm{~min}$. Excess BSA was drained. These sections were then incubated in respective primary antibody overnight at $4^{\circ} \mathrm{C}$ in a humidified chamber. For the negative control, slide was incubated in PBS. Primary antibodies against IL- $1 \beta$, IL-2, and IL-4 raised in rabbit were used at $1: 50$ dilution. After being rinsed in PBST (0.1\% Tween-20 in 
PBS), sections were then incubated for $1 \mathrm{~h}$ at $37^{\circ} \mathrm{C}$ with HRPgoat anti-rabbit diluted 1:200 in PBS. After three washes for $5 \mathrm{~min}$ in PBST, the sections were incubated in substrate diaminobenzidine for 3-5 min until the color developed. Then, the sections were counterstaining with hematoxylin for $3 \mathrm{~min}$. After brief washes in distilled water, the slides were dehydrated in grades of ethanol, cleared for $20 \mathrm{~min}$ in xylene. Pictures were taken by the Canon Micro-imaging System and analyzed with Image-Pro Plus 6.0 to measure average optical intensity (AOI).

2.7. Western Blot for Endometrial IL-1 $\beta, I L-4$, and IL-10 Protein Detection. Total protein was extracted from the endometrial implantation site tissues which were homogenated and lyzed in Mammal tissue protein extraction reagent, supplemented with protease inhibitor cocktail and phenylmethylsulfonylfluoride (PMSF), then centrifuged at $13201 \mathrm{~g}$ for $10 \mathrm{~min}$ at $4^{\circ} \mathrm{C}$. The supernatants were collected to quantify the protein concentration with the BCA protein assay kit. Uterine extracts ( $100 \mu \mathrm{g}$ protein) were mixed with sample buffer, boiled for $10 \mathrm{~min}$, and ran on a $12 \%$ SDSPAGE gel $(100 \mathrm{v}, 2 \mathrm{~h})$. Separated proteins on the gel were transferred to nitrocellulose membranes. The membranes were blocked with 5\% non-fat-dry milk in PBST for $2 \mathrm{~h}$ at room temperature and incubated overnight at $4{ }^{\circ} \mathrm{C}$ with antibodies to $\beta$-actin, IL- $1 \beta$, IL- 4 , or IL-10 diluted $1: 200$, $1: 50,1: 50$, and $1: 50$, respectively. Following four washes with PBST ( $5 \mathrm{~min}$ each), the membranes were lucifugally incubated with the DyLight 800-Labeled Antibody To Rabbit $\operatorname{IgG}(\mathrm{H}+\mathrm{L})$ diluted $1: 10000$ at room temperature for $1 \mathrm{~h}$. After lucifugally washing with PBST, the membranes were detected by near infrared double-color laser imaging system. The pictures were analyzed with Image J to calculate the gray scale ratio of $\beta$-actin.

2.8. Real-Time PCR for Endometrial IL-1 $\beta, I L-2, I L-4$, and IL10 Expression. Total RNA was extracted from endometrial homogenized tissue with Trizol reagent according to the manufacturer's instructions. RNA purity and concentration were measured by Nucleic Acid/Protein Analyzer. $1 \mu \mathrm{g}$ of extracted total RNA was reverse transcribed with PrimeScript RT reagent Kit in accordance with the manufacturer's instructions. The cDNA was kept at $-20^{\circ} \mathrm{C}$ prior to $\mathrm{PCR}$ amplification. Real-Time PCR reactions were performed in 48 well optical PCR plates using an Applied Biosystems StepOne Real-Time PCR System according to the manufacturer's instructions. $2^{-\Delta \Delta C T}$ was used for analyzing the data. Primer sequence:

$\beta$-actin

Forward primer: 5'-GGAGATTACTGCCCTGGCTCCTA-3'

Reverse primer: 5'-GACTCATCGTACTCCTGCTTGCTG-3'

IL- $1 \beta$

Forward primer: 5'-GCTGTGGCAGCTACCTATGTCTTG-3'
Reverse primer: 5'-AGGTCGTCATCATCCCACGAG-3'

IL-2

Forward primer: $5^{\prime}$-GCAGCGTGTGTTGGATTTGAC-3'

Reverse primer: 5'-GCTCATCATCGAATTGGCACTC-3'

IL-4

Forward primer: $5^{\prime}$-TGCACCGAGATGTTTGTACCAGA-3'

Reverse primer: 5'-TTGCGAAGCACCCTGGAAG-3'

IL-10

Forward primer: 5'-CAGACCCACATGCTCCGAGA-3'

Reverse primer: 5'-CAAGGCTTGGCAACCCAAGTA-3'

2.9. Statistics. All data had a normal distribution presented as mean \pm standard deviation (SD) and analysed by SPSS17.0 Statistical Software. Statistical significance was determined by one-way analysis of variance (ANOVA) followed by Dunnett's T3 test for data with equal variances not assumed. For data with equal variances assumed, ANOVA followed by LSD test was used. A probability of less than 0.05 was considered to be statistically significant.

\section{Results}

3.1. Implantation of Embryos on D8. Compared with group $\mathrm{N}$, the number of embryos was significantly lower in group $\mathrm{M}(P<0.05)$. In addition, the size of embryos was smaller in group $M$ than in group $N$. Compared with group $M$, the number of embryos was significantly higher in groups $\mathrm{A}$ and $\mathrm{H}(P<0.05)$, and the size of embryos was larger in groups $\mathrm{A}$ and $\mathrm{H}$ (Figure 1 and Table 1 ).

3.2. Expression of $I L-1 \beta, I L-2, I L-4$, and $I L-10$ in Serum. Compared with group $\mathrm{N}$, the serum IL- $1 \beta$ level was significantly higher in group M on D5 and D6 $(P<0.05)$. And there was a significant reduction in the expression of IL-1 $\beta$ in groups $\mathrm{A}$ and $\mathrm{H}$ when compared with group $\mathrm{M}$ on D5 and D6 $(P<0.05)$. Compare with group $\mathrm{N}$, the serum IL-2 level was significantly higher in group M on D6 and D8 $(P<$ $0.05)$, while, compared with group $M$, there was a significant reduction in the expression of IL-2 in group A on D8 and in group $\mathrm{H}$ on D6 and D8 $(P<0.05)$. Compared with group $\mathrm{N}$, the serum IL-4 level was significantly lower in group $M$ on D5 and D6 $(P<0.05)$, while, compared with group $M$, there was a significant increase in the expression of IL-4 in group A on D5 and in group H on D5 and D8 $(P<0.05)$. Compared with group $\mathrm{N}$, the serum IL-10 level was significantly lower in group $\mathrm{M}$ on D6 $(P<0.05)$. And there was a significant 


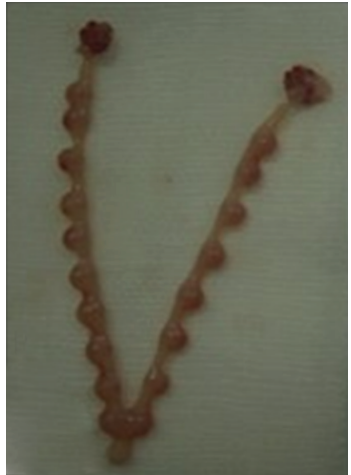

(a)

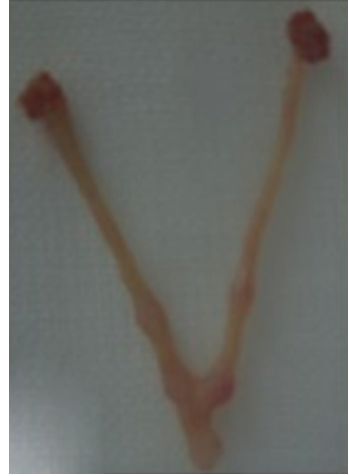

(b)

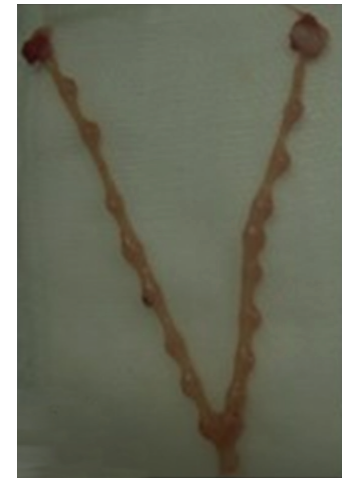

(c)

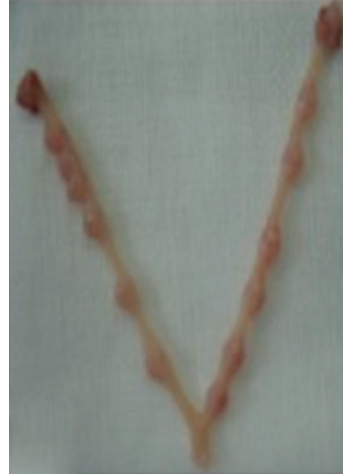

(d)

Figure 1: (a) Uterus of group N on D8; (b) uterus of group M on D8; (c) uterus of group A on D8; (d) uterus of group H on D8.

TABLE 1: Comparison of embryo number on Day 8.

\begin{tabular}{lcc}
\hline Group & Number of rats & Embryo number \\
\hline $\mathrm{N}$ & 6 & $13.50 \pm 2.27$ \\
$\mathrm{M}$ & 6 & $3.6 \pm 1.52^{*}$ \\
$\mathrm{~A}$ & 6 & $9.88 \pm 3.14 \Delta$ \\
$\mathrm{H}$ & 6 & $11.58 \pm 2.64 \Delta$ \\
\hline
\end{tabular}

Value $=$ mean \pm SD.

* represents that there is significant difference when $\mathrm{M}$ is compared with $\mathrm{N}$ $(P<0.05)$.

$\Delta$ represents that there is significant difference when $\mathrm{A}$ or $\mathrm{H}$ is compared with $\mathrm{M}(P<0.05)$.

increase in the expression of IL-10 in groups $\mathrm{A}$ and $\mathrm{H}$ when compared with group M on D6 and D8 $(P<0.05)$ (Table 2).

\subsection{Expression of Endometrial IL-1 $\beta, I L-2, I L-4$, and IL-10 Protein}

3.3.1. Outcome of ELISA. The IL- $1 \beta$ protein concentration was significantly elevated in group $\mathrm{M}$ compared with group $\mathrm{N}$ on D5 $(P<0.05)$, while, compared with group $\mathrm{M}$, there was a significant decrease in IL- $1 \beta$ protein concentration in group A on D5 and D8 and in group H on D5 $(P<0.05)$. The IL-2 protein concentration was significantly elevated in group M compared with group $\mathrm{N}$ on $\mathrm{D} 5(P<0.05)$, while, compared with group $\mathrm{M}$, there was a significant decrease in IL-2 protein concentration in groups $\mathrm{A}$ and $\mathrm{H}$ on D5 $(P<0.05)$. The IL-4 protein concentration was significantly reduced in group $\mathrm{M}$ compared with group $\mathrm{N}$ on $\mathrm{D} 5, \mathrm{D}$, and D8 $(P<0.05)$, while, compared with group $\mathrm{M}$, there was a significant rise in IL-4 protein concentration in groups $\mathrm{A}$ and $\mathrm{H}$ on D5, D6, and D8 $(P<0.05)$. The IL-10 protein concentration was significantly reduced in group $\mathrm{M}$ compared with group $\mathrm{N}$ on $\mathrm{D} 5(P<0.05)$, while, compared with group $\mathrm{M}$, there was a significant rise in IL-10 protein concentration in groups A and $\mathrm{H}$ on D5 $(P<0.05)$ (Table 3$)$.

3.3.2. Outcome of Immunohistochemistry. Compared with group $\mathrm{N}$, the endometrial IL- $1 \beta$ protein level was significantly increasing in group $\mathrm{M}$ on D5, D6, and D8 $(P<$
0.05 ), while, compared with group $M$, there was a significant diminution in the expression of IL- $1 \beta$ protein in groups $\mathrm{A}$ and $\mathrm{H}$ on D5 and D8 $(P<0.05)$. Compared with group $\mathrm{N}$, the endometrial IL-2 protein level was significantly increasing in group $\mathrm{M}$ on D5, D6, and D8 $(P<0.05)$, while, compared with group $M$, there was a significant diminution in the expression of IL-2 protein in groups A and $\mathrm{H}$ on D5, D6, and $\mathrm{D} 8(P<0.05)$. Compared with group $\mathrm{N}$, the endometrial IL-4 protein level was significantly decreasing in group $\mathrm{M}$ on D5 and D6 $(P<0.05)$, while, compared with group $\mathrm{M}$, there was a significant elevation in the expression of IL-4 protein in groups A and $\mathrm{H}$ on D5 and D6 $(P<0.05)$ (Figures 2 and 3$)$.

3.3.3. Outcome of Western Blot. Compared with group N, the endometrial IL-1 $\beta$ protein level was significantly increasing in group M on D5 and D8 $(P<0.05)$, while, compared with group $\mathrm{M}$, there was a significant diminution in the expression of IL- $1 \beta$ protein in groups A and $\mathrm{H}$ on D5 $(P<0.05)$. Compared with group $\mathrm{N}$, the endometrial IL-4 protein level was significantly decreasing in group $\mathrm{M}$ on D5, D6, and D8 $(P<0.05)$, while, compared with group $\mathrm{M}$, there was a significant elevation in the expression of IL-4 protein in groups $\mathrm{A}$ and $\mathrm{H}$ on D5, D6, and D8 $(P<0.05)$. Compared with group $\mathrm{N}$, the endometrial IL-10 protein level was significantly decreasing in group $\mathrm{M}$ on D5, D6, and D8 $(P<$ 0.05 ), while, compared with group $M$, there was a significant elevation in the expression of IL-10 protein in group A on D5 and D6 and in group H on D5 and D8 $(P<0.05)$ (Figure 4$)$.

3.4. Expression of Endometrial $I L-1 \beta, I L-2, I L-4$, and $I L-10$ $m R N A$. The IL- $1 \beta$ mRNA concentration was significantly lower in group $\mathrm{M}$ compared with group $\mathrm{N}$ on D5 $(P<$ 0.05 ), while, compared with group $M$, there was a significant increase in IL- $1 \beta$ mRNA concentration in groups $A$ and H on D5 $(P<0.05)$. The IL-2 mRNA concentration was significantly elevated in group $\mathrm{M}$ compared with group $\mathrm{N}$ on D5, D6, and D8 $(P<0.05)$, while, compared with group $\mathrm{M}$, there was a significant decrease in IL-2 mRNA concentration in group A on D5, D6, and D8 and in group $\mathrm{H}$ on D5 and D6 $(P<0.05)$. The IL-4 mRNA concentration was significantly increasing in group $\mathrm{M}$ compared with group $\mathrm{N}$ on D5 and 
TABLE 2: Comparison of serum cytokines concentration.

\begin{tabular}{lccccc}
\hline Cytokine group & Day & N & M & A & H \\
\hline \multirow{3}{*}{ IL-1 $\beta$} & D5 & $50.07 \pm 5.22$ & $76.86 \pm 15.35^{*}$ & $50.00 \pm 6.81 \Delta$ & $42.62 \pm 7.58 \Delta$ \\
& D6 & $50.50 \pm 3.91$ & $68.26 \pm 1.25^{*}$ & $43.65 \pm 4.38 \Delta$ & $45.11 \pm 1.84 \Delta$ \\
& D8 & $27.12 \pm 2.77$ & $47.74 \pm 9.44$ & $46.57 \pm 1.67$ & $72.84 \pm 2.83$ \\
IL-2 & D5 & $86.13 \pm 4.74$ & $90.02 \pm 7.03$ & $74.84 \pm 15.42$ & $43.05 \pm 11.64$ \\
& D6 & $39.46 \pm 8.84$ & $61.02 \pm 6.66^{*}$ & $57.70 \pm 8.15$ & $54.45 \pm 7.82 \Delta$ \\
& D8 & $37.24 \pm 0.64$ & $80.14 \pm 6.66^{*}$ & $52.69 \pm 11.69 \Delta$ & $30.00 \pm 5.42 \Delta$ \\
IL-4 & D5 & $50.67 \pm 2.08$ & $16.33 \pm 4.72^{*}$ & $43.00 \pm 1.00 \Delta$ & $20.20 \pm 3.63$ \\
& D6 & $24.25 \pm 2.50$ & $17.00 \pm 1.87^{*}$ & $18.40 \pm 1.52$ & $44.00 \pm 16.00 \Delta$ \\
& D8 & $25.80 \pm 7.26$ & $18.00 \pm 2.64$ & $33.67 \pm 12.89$ & $47.19 \pm 1.48 \Delta$ \\
IL-10 & D5 & $141.87 \pm 29.54$ & $84.45 \pm 7.35$ & $93.88 \pm 14.68$ & $455.29 \pm 37.66 \Delta$ \\
& D6 & $113.07 \pm 14.63$ & $34.63 \pm 13.02^{*}$ & $207.84 \pm 40.27 \Delta$ & $60.51 \pm 3.61 \Delta$ \\
\hline
\end{tabular}

Values are mean $\pm \mathrm{SD}(\mathrm{pg} / \mathrm{mL})$.

* represents that there is significant difference when $\mathrm{M}$ is compared with $\mathrm{N}(P<0.05)$.

$\Delta$ represents that there is significant difference when $\mathrm{A}$ or $\mathrm{H}$ is compared with $\mathrm{M}(P<0.05)$.

TABLE 3: Comparison of endometrium cytokines protein concentration.

\begin{tabular}{|c|c|c|c|c|c|}
\hline Cytokine group & Day & $\mathrm{N}$ & M & A & $\mathrm{H}$ \\
\hline \multirow[t]{3}{*}{ IL- $1 \beta$} & D5 & $35.47 \pm 2.37$ & $163.73 \pm 6.62^{*}$ & $59.03 \pm 20.02 \Delta$ & $95.03 \pm 3.36 \Delta$ \\
\hline & D6 & $52.80 \pm 11.90$ & $55.82 \pm 14.90$ & $49.13 \pm 1.22$ & $46.52 \pm 10.4$ \\
\hline & D8 & $74.80 \pm 11.75$ & $111.55 \pm 9.34$ & $65.57 \pm 3.01 \Delta$ & $71.24 \pm 23.91$ \\
\hline \multirow[t]{3}{*}{ IL-2 } & D5 & $51.78 \pm 8.09$ & $79.67 \pm 10.65^{*}$ & $60.87 \pm 9.83 \Delta$ & $63.55 \pm 12.06 \Delta$ \\
\hline & D6 & $40.63 \pm 0.89$ & $53.44 \pm 5.63$ & $44.51 \pm 2.15$ & $42.02 \pm 3.83$ \\
\hline & D8 & $55.84 \pm 3.48$ & $68.81 \pm 11.49$ & $66.47 \pm 14.63$ & $61.95 \pm 12.82$ \\
\hline \multirow[t]{3}{*}{ IL-4 } & D5 & $189.50 \pm 10.61$ & $40.00 \pm 10.89^{*}$ & $72.75 \pm 23.04 \Delta$ & $67.00 \pm 13.47 \Delta$ \\
\hline & D6 & $58.33 \pm 17.74$ & $34.67 \pm 9.50^{*}$ & $74.50 \pm 16.05 \Delta$ & $61.33 \pm 7.09 \Delta$ \\
\hline & D8 & $66.33 \pm 3.06$ & $36.00 \pm 5.57^{*}$ & $70.00 \pm 18.88 \Delta$ & $76.75 \pm 23.04 \Delta$ \\
\hline \multirow[t]{3}{*}{ IL-10 } & D5 & $175.79 \pm 9.42$ & $127.94 \pm 10.25^{*}$ & $185.32 \pm 9.39 \Delta$ & $161.02 \pm 15.32 \Delta$ \\
\hline & D6 & $101.68 \pm 21.22$ & $268.95 \pm 21.14^{*}$ & $256.29 \pm 31.13$ & $264.53 \pm 20.55$ \\
\hline & D8 & $119.98 \pm 31.77$ & $60.12 \pm 1.24$ & $107.89 \pm 18.16$ & $126.30 \pm 1.84 \Delta$ \\
\hline
\end{tabular}

Values are mean $\pm \mathrm{SD}(\mathrm{pg} / \mathrm{mL})$.

* represents that there is significant difference when $\mathrm{M}$ is compared with $\mathrm{N}(P<0.05)$.

$\Delta$ represents that there is significant difference when $\mathrm{A}$ or $\mathrm{H}$ is compared with $\mathrm{M}(P<0.05)$.

D6 $(P<0.05)$, while, compared with group $\mathrm{M}$, there was a significant drop in IL-4 mRNA concentration in groups A and $\mathrm{H}$ on D5, D6, and D8 $(P<0.05)$. The IL-10 mRNA concentration was significantly reduced in group $\mathrm{M}$ compared with group $\mathrm{N}$ on $\mathrm{D} 8(P<0.05)$, while, compared with group $\mathrm{M}$, there was a significant rise in IL-10 mRNA concentration in groups $\mathrm{A}$ and $\mathrm{H}$ on D8 $(P<0.05)$ (Figure 5).

\section{Discussion}

Mifepristone is the classical antagonist to progestin which has obvious lysis to corpus luteum and resistance to implantation [18]. The development of endometrium was restrained by mifepristone in corpus luteal phase which caused the nonsynchronous growth in endometrium and blastocyst and interfered blastocyst implantation [19]. Mifepristone could blocks progesterone receptors, yet in this study, progesterone counteracted the anti-implantation effect of mifepristone which suggests that excess progesterone could displace the anti-progesterone receptor. Earlier research showed that acupuncture could reverse the implantation resistance of mifepristone, upregulate P level, and significantly increase the average implantation blastocysts number [20]. In the study, the average implantation blastocysts number was notably higher in group A than in group $M$, which confirmed the effect of acupuncture on antagonizing mifepristone. Acupuncture could improve the poor receptive state of endometrium due to mifepristone, so as to promote the success of blastocyst implantation.

Successful pregnancy has been described as a "Th-2 phenomenon" [14]. Recently, significantly higher serum levels of Th2 cytokines, IL-6 and IL-10 were detected in normal pregnancy compared with unexplained recurrent pregnancy losses and significantly higher serum levels of the Th1 cytokine, IFN- $\gamma$ were present in women with recurrent pregnancy losses, compared with normal pregnancy [21]. 

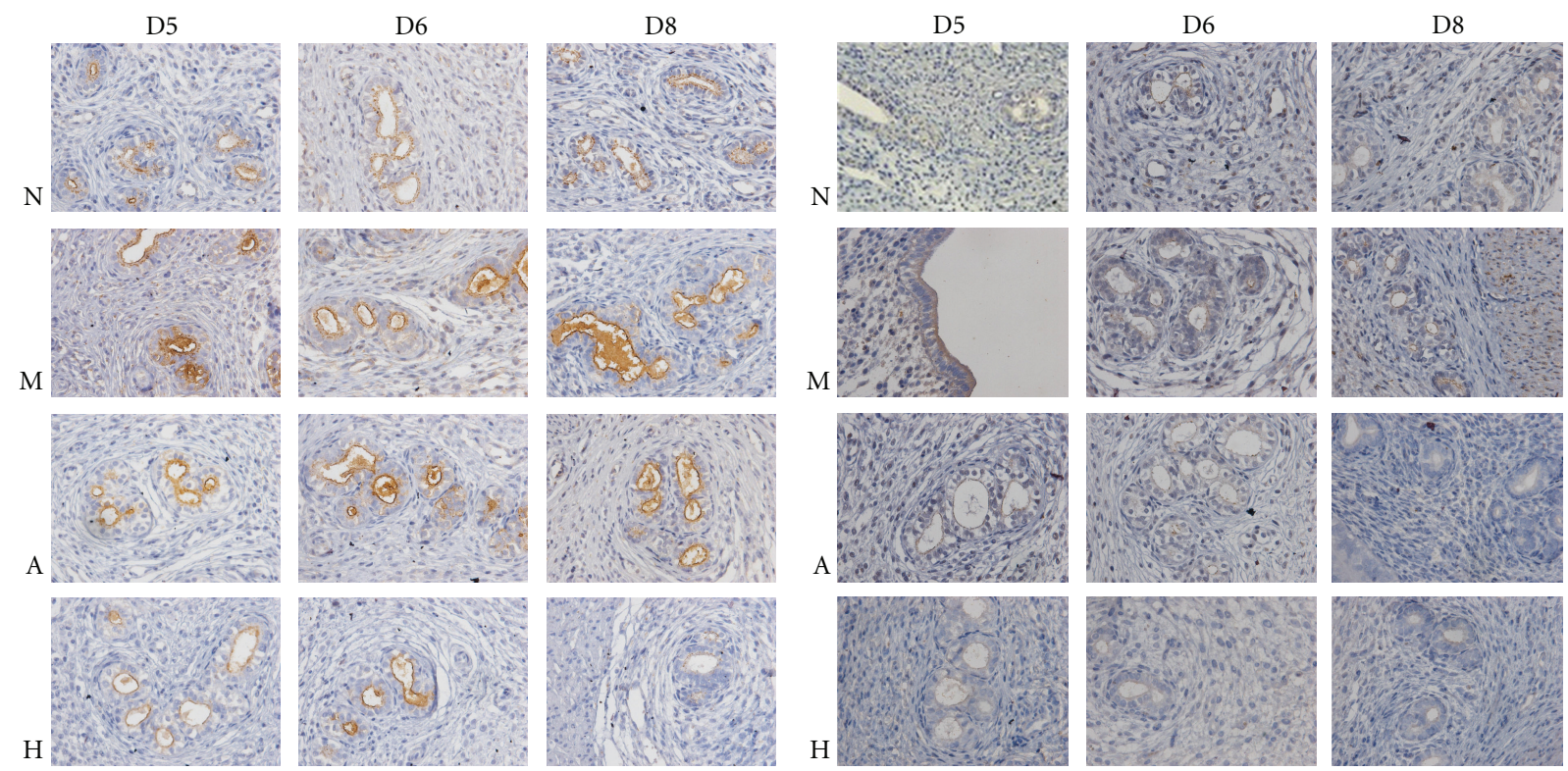

(a)

(b)
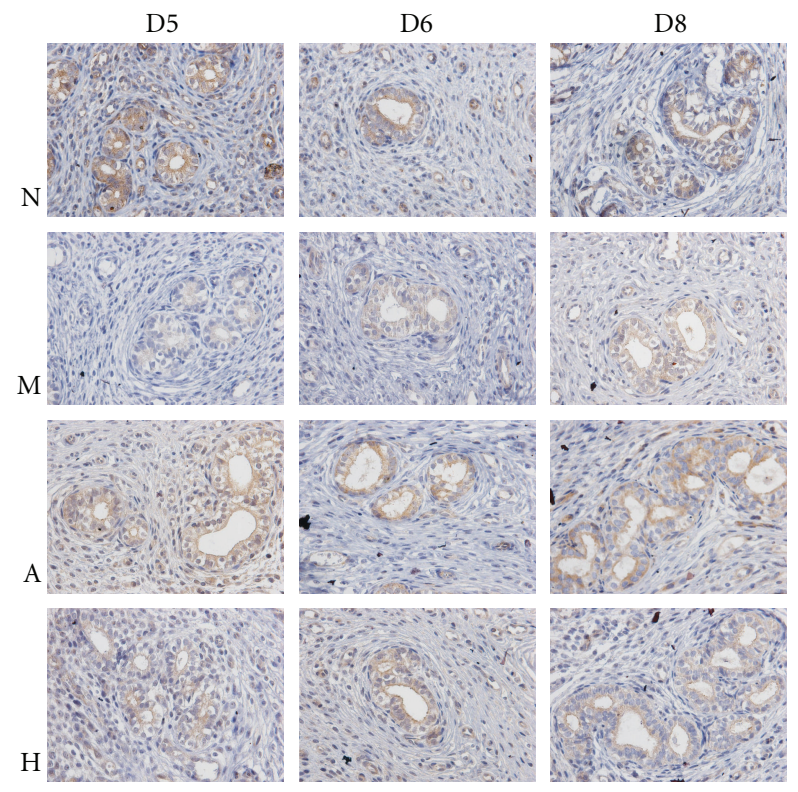

(c)

FIGURE 2: Immunohistochemical staining for the expression of endometrial IL- $1 \beta$, IL-2, and IL-4. Original magnificasion: $\times 400$. Claybank means positive expression. (a) IL- $1 \beta$ protein in each group on D5, D6, and D8; (b) IL-2 protein in each group on D5, D6, and D8; (c) IL-4 protein in each group on D5, D6, and D8. IL-1 $\beta$, IL-2, and IL-4 mainly expressed in luminal and glandular epithelium.

IL-2 is a Th1 cytokine that enhances the activity and formation of cytotoxic cells. IL-2 also stimulates TNF $\alpha$, IL1 , and IFN $\gamma$ secretion which are harmful to implantation [22]. The blastocyst implantation of rat occurs on D4 or D5. In this experiment, the expression of endometrial IL2 mRNA and protein were notably lower in groups $\mathrm{N}, \mathrm{A}$, and $\mathrm{H}$ than in group $\mathrm{M}$ on $\mathrm{D}$, which verifies that IL-2 is a harmful factor for implantation and demonstrates that acupuncture could effectively reduce the endometrial IL-2 mRNA and protein level and inhibit the cytotoxic effect of IL-2, so as to provide a better environment for blastocysts. However, there is no significant difference among groups in serum IL-2 concentration until D6 or D8. The possible reason might be that IL-2 is mainly produced in uterine during the implantation phase, and there is a delay from secreting in uterine to detecting in serum.

Many events that occur in the fetomaternal interface involve IL-4. IL-4 secreted by endometrium-infiltrating lymphocytes stimulates production of LIF in endometrial tissue [23], which plays a crucial role in implantation and placentation in several species [24]. IL-4 also promotes hCG release in trophoblasts [25], and the released hCG induces production of progesterone from the corpus luteum, which promotes production of Th2 cytokines [26], and displays an 

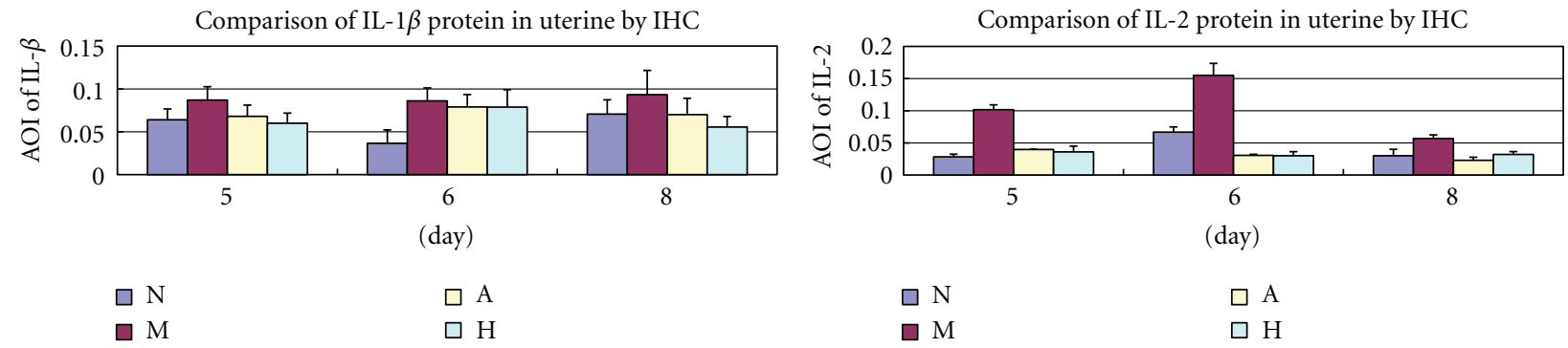

(a)

(b)

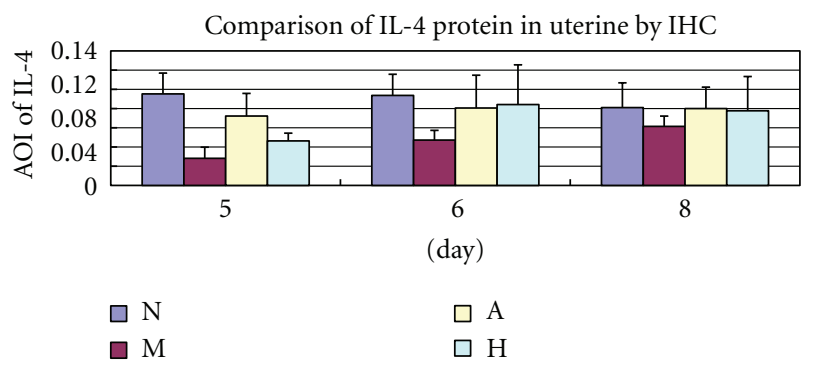

(c)

Figure 3: Expression of endometrial protein (a) IL-1 $\beta$; (b) IL-2; (c) IL-4. AOI means average optical intensity. IHC means immunohistochemistry. ${ }^{*}$ represents that there is significant difference when $\mathrm{M}$ is compared with $\mathrm{N}(P<0.05)$. $\Delta$ represents that there is significant difference when $\mathrm{A}$ or $\mathrm{H}$ is compared with $\mathrm{M}(P<0.05)$.

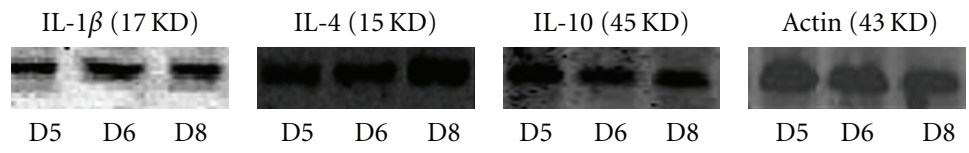

(a)
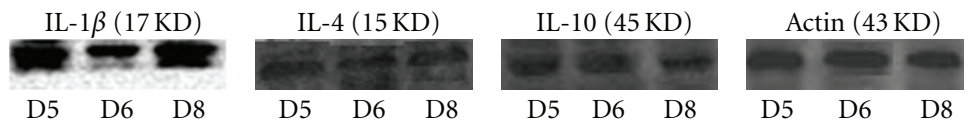

(b)
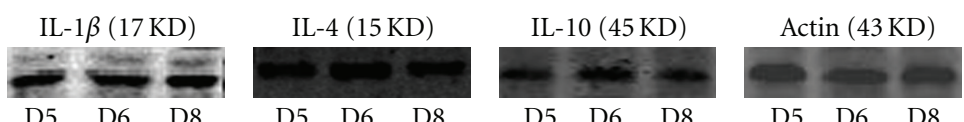

(c)
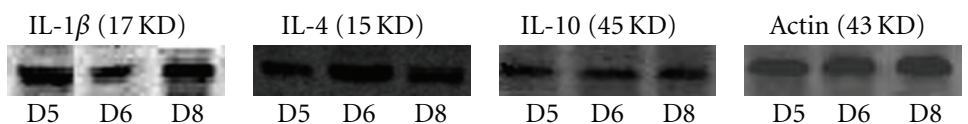

(d)

Figure 4: Expression of endometrial IL-1 $\beta$, IL-4, and IL-10 proteins on D5, D6, and D8 in (a) group N; (b) group M; (c) group A; (d) group $\mathrm{H}$.

antiabortive effect [27]. Our results indicate that endometrial IL-4 protein level was significantly higher in groups $\mathrm{N}, \mathrm{A}$, and $\mathrm{H}$ than in group $\mathrm{M}$ on $\mathrm{D} 5$, which is a cue that IL-4 plays a positive role in the process of implantation. At the same time, the results show that acupuncture could promote implantation by elevating the expression of endometrial IL-4 protein.

IL-10 is one of the cytokines produced by Th2 lymphocytes, whose immunity is necessary for successful pregnancy outcome [8]. IL-10 is an anti-inflammatory cytokine widely present in tissues and fluids during gestation [28], including cyto- and syncytiotrophoblast as well as decidual mononuclear cells/macrophages and NK cells $[8,29,30]$. Decidual monocytes/macrophages and NK cells spontaneously secrete IL-4 and IL-10 in early pregnancy [30]. High levels of IL-10 have also been found in amniotic fluid and maternal serum $[8,27,31,32]$. IL-10 production was also increased in control women compared with women that were unexplained infertile [33]. A large increase in IL-10 from day 14 to day 21 of 


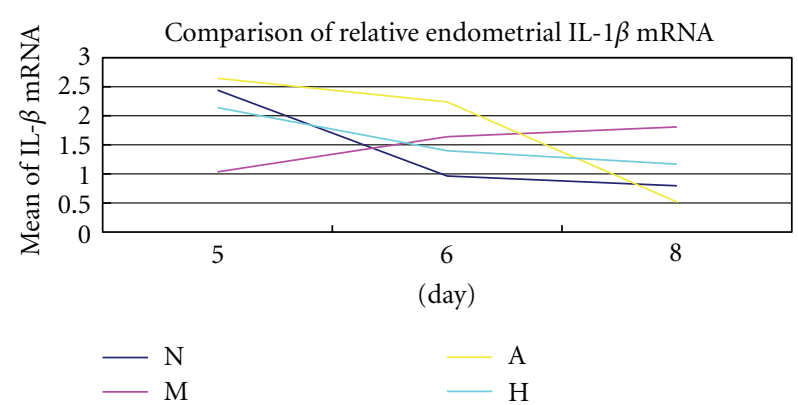

(a)

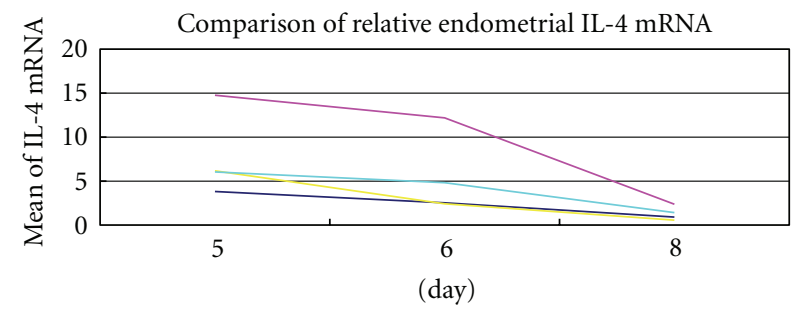

$\mathrm{N}$
$\mathrm{M}$$\quad \mathrm{A}$

(c)

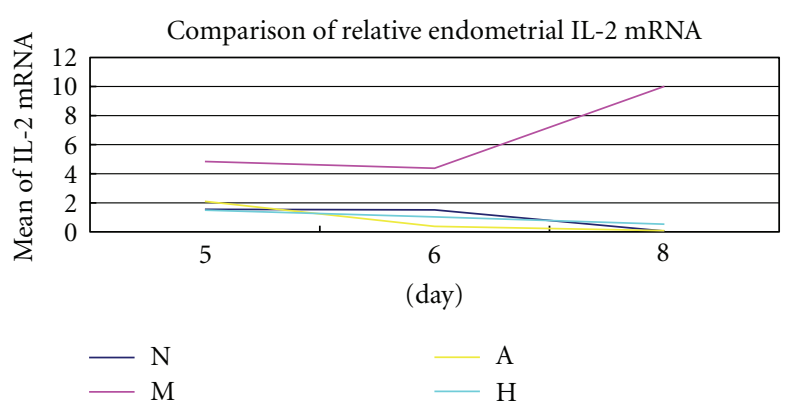

(b)
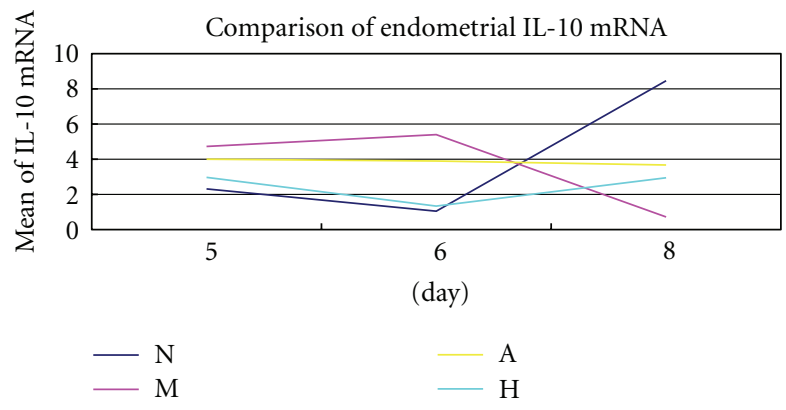

(d)

FIgURE 5: Expression of endometrial mRNA (a) IL-1 $\beta$; (b) IL-2; (c) IL-4; (d) IL-10.

pregnancy in women with normal pregnancy outcome compared with those with pregnancy failure was seen in another study [34]. The protection function of IL-10 in implantation is again confirmed in this experiment. Acupuncture could stimulate endometrium to produce IL-10 protein which has resistance to the effect of mifepristone. Serum IL-10 level had a striking increase on D6 in groups $\mathrm{N}, \mathrm{A}$, and $\mathrm{H}$ compared with group $\mathrm{M}$ which is not consistent with endometrial IL10 level. The delay may be taken into consideration.

In the recurrent implantation failure women, statistically significant elevated levels of IL- $1 \beta$ and reduced levels of IL10 were found [35]. IL-1 stimulates LIF receptor antagonist and decreases implantation rate in the mouse [36]. A more recent study has shown that low plasma concentrations of IL-1 $\beta$ and high plasma concentrations of IL-1 Ra are associated with good-quality embryos and increased presence of clinical pregnancies [37]. IL- $1 \beta$ negatively affects early stages of pregnancy establishment acting as embryo implantation inhibitors $[38,39]$. In addition, Boomsma et al. demonstrated that clinical pregnancy was associated with a significantly lower concentration of IL-1 in endometrial secretions of women [40]. The results of IL- $1 \beta$ protein level in this study suggest that IL- $1 \beta$ has a deletious effect on implantation as reported in other literatures and also hint that endometrial IL-1 $\beta$ protein could be effectively reduced by acupuncture treatment. There is a discrepancy between endometrial mRNA expression and protein level in IL- $1 \beta$, IL- 4 which might be coursed by the regulation for protein translation. The high protein level might give a negative feedback to the mRNA expression. Endometrial proteins of IL-4 and IL-10 were highest on D5 in group $\mathrm{N}$, but the peak time for group $\mathrm{M}$ was on D6 or even on D8 which prompts that the expression of Th2 cytokines is postponed by mifepristone which retards development of endometrium leading to implantation failure. Though group A reached the height on D6, acupuncture therapy improved the poor receptive state of endometrium by stimulating the expression of Th2 cytokines and reversed the harmful effect of mifepristone to some extent on D5.

In conclusion, we hypothesis that through a series of nerve-physiology-endocrine activities, acupuncture changes the immune microenvironment of endometrium by altering the expression of cytokines in implantation failure uterus including promoting Th2 cytokines such as IL-4 and IL10 secretion and inhibiting Th1 cytokines including IL- $1 \beta$ and IL-2 secretion to improve blastocyst implantation. Next, we have to do the corresponding clinical trials to prove whether acupuncture can produce the same effect in infertile patients. Further rigorous research is needed to confirm the effectiveness of acupuncture.

\section{Acknowledgment}

Financial support is received from National Natural Science Foundation: S-049-09-10-20, China.

\section{References}

[1] H. Song, H. Lim, K. das Sanjoy et al., "Dysrgulation of EGF family of growth factors and COX-2 in the uterus during the preattachment and attachment reactions of the blastocyst with the luminal epithelium correlates with implantation failure in LIF-deficient mice," Molecular Endocrinology, vol. 14, no. 8, pp. 1147-1161, 2000.

[2] D. Navot, R. T. Scott, K. Droesch, L. L. Veeck, H. C. Liu, and Z. Rosenwaks, "The window of embryo transfer and 
the efficiency of human conception in vitro," Fertility and Sterility, vol. 55, no. 1, pp. 114-118, 1991.

[3] M. Cavagna and J. C. Mantese, "Biomarkers of endometrial receptivity-a review," Placenta, vol. 24, supplement B, pp. S39S47, 2003.

[4] R. G. Edwards, "Clinical approaches to increasing uterine receptivity during human implantation," Human Reproduction, vol. 10, no. 2, pp. 60-66, 1995.

[5] T. C. S. Bonetti, R. Salomao, M. Brunialti, D. P. A. F. Braga, E. Borges, and I. D. C. G. Silva, "Cytokine and hormonal profile in serum samples of patients undergoing controlled ovarian stimulation: interleukin-1 predicts ongoing pregnancy," Human Reproduction, vol. 25, no. 8, pp. 2101-2106, 2010.

[6] A. Trundley and A. Moffett, "Human uterine leukocytes and pregnancy," Tissue Antigens, vol. 63, no. 1, pp. 1-12, 2004.

[7] L. A. Salamonsen, N. J. Hannan, and E. Dimitriadis, "Cytokines and chemokines during human embryo implantation: roles in implantation and early placentation," Seminars in Reproductive Medicine, vol. 25, no. 6, pp. 437-444, 2007.

[8] N. Bechi, F. Ietta, R. Romagnoli et al., "Environmental levels of para-nonylphenol are able to affect cytokine secretion in human placenta," Environmental Health Perspectives, vol. 118, no. 3, pp. 427-431, 2010.

[9] G. Chaouat, S. Dubanchet, and N. Ledée, "Cytokines: important for implantation?" Journal of Assisted Reproduction and Genetics, vol. 24, no. 11, pp. 491-505, 2007.

[10] A. Moffett and C. Loke, "Implantation, embryo-maternal interactions, immunology and modulation of the uterine environment-a workshop report," Placenta, vol. 27, pp. 54-55, 2006.

[11] B. C. Paria, J. Reese, S. K. Das, and S. K. Dey, "Deciphering the cross-talk of implantation: advances and challenges," Science, vol. 296, no. 5576, pp. 2185-2188, 2002.

[12] S. Saito, "Cytokine cross-talk between mother and the embryo/placenta," Journal of Reproductive Immunology, vol. 52, no. 1-2, pp. 15-33, 2001.

[13] S. Schäfer-Somi, "Cytokines during early pregnancy of mammals: a review," Animal Reproduction Science, vol. 75, no. 1-2, pp. 73-94, 2003.

[14] T. G. Wegmann, H. Lin, L. Guilbert, and T. R. Mosmann, "Bidirectional cytokine interactions in the maternal-fetal relationship: is successful pregnancy a TH2 phenomenon?" Immunology Today, vol. 14, no. 7, pp. 353-356, 1993.

[15] L. G. Westergaard, Q. Mao, M. Krogslund, S. Sandrini, S. Lenz, and J. Grinsted, "Acupuncture on the day of embryo transfer significantly improves the reproductive outcome in infertile women: a prospective, randomized trial," Fertility and Sterility, vol. 85, no. 5, pp. 1341-1346, 2006.

[16] W. E. Paulus, M. Zhang, E. Strehler, I. El-Danasouri, and K. Sterzik, "Influence of acupuncture on the pregnancy rate in patients who undergo assisted reproduction therapy," Fertility and Sterility, vol. 77, no. 4, pp. 721-724, 2002.

[17] X. B. Hua, C. R. Li, and H. L. Zhou, "Preparation of acupuncture atlas of rat," Animal Experimentation, vol. 3, no. 1, pp. 1-5, 1991.

[18] S. L. Shang, "The clinical application of mifepristone in the birth control," Medical Recapitulate, vol. 12, no. 16, pp. 10111013, 2006.

[19] I. C. Bagchi, Q. Li, Y. P. Cheon, S. R. Mantena, A. Kannan, and M. K. Bagchi, "Use of the progesterone receptor antagonist RU 486 to identify novel progesterone receptor-regulated pathways in implantation," Seminars in Reproductive Medicine, vol. 23, no. 1, pp. 38-45, 2005.
[20] X. Y. Liu, G. Y. Huang, and M. M. Zhang, "Preliminary study on the mechanisms of acupuncture in promoting embryo implantation in rats," Chinese Journal of Integrated Traditional and Western Medicine, vol. 27, no. 7, pp. 633-636, 2007.

[21] R. Raghupathy, M. Makhseed, F. Azizieh, N. Hassan, M. AlAzemi, and E. Al-Shamali, "Maternal Th1- and Th2-type reactivity to placental antigens in normal human pregnancy and unexplained recurrent spontaneous abortions," Cellular Immunology, vol. 196, no. 2, pp. 122-130, 1999.

[22] T. Diemer, D. B. Hales, and W. Weidner, "Immune-endocrine interactions and Leydig cell function: the role of cytokines," Andrologia, vol. 35, no. 1, pp. 55-63, 2003.

[23] M. P. Piccinni and S. Romagnani, "Regulation of fetal allograft survival by hormone-controlled Th1- and Th2-type cytokines," Immunologic Research, vol. 15, no. 2, pp. 141-150, 1996.

[24] C. L. Stewart, "The role of leukemia inhibitory factor (LIF) and other cytokines in regulating implantation in mammals," Annals of the New York Academy of Sciences, vol. 734, pp. 157$165,1994$.

[25] S. Saito, N. Harada, N. Ishii et al., "Functional expression on human trophoblasts of interleukin 4 and interleukine 7 receptor complexes with a common gamma chain," Biochemical and Biophysical Research Communications, vol. 231, pp. 429-434, 1997.

[26] J. Szekeres-Bartho and T. G. Wegmann, "A progesteronedependent immunomodulatory protein alters the Th1/Th2 balance," Journal of Reproductive Immunology, vol. 31, no. 12, pp. 81-95, 1996.

[27] J. Szekeres-Bartho, G. Par, L. Szereday, C. Y. Smart, and I. Achatz, "Progesterone and non-specific immunologic mechanisms in pregnancy," American Journal of Reproductive Immunology, vol. 38, no. 3, pp. 176-182, 1997.

[28] F. Gotsch, R. Romero, J. P. Kusanovic et al., "The antiinflammatory limb of the immune response in preterm labor, intra-amniotic infection/inflammation, and spontaneous parturition at term: a role for interleukin-10," Journal of MaternalFetal and Neonatal Medicine, vol. 21, no. 8, pp. 529-547, 2008.

[29] N. Hanna, I. Hanna, M. Hleb et al., "Gestational age-dependent expression of IL-10 and its receptor in human placental tissues and isolated cytotrophoblasts," Journal of Immunology, vol. 164, no. 11, pp. 5721-5728, 2000.

[30] C. Lidström, L. Matthiesen, G. Berg, S. Sharma, J. Ernerudh, and C. Ekerfelt, "Cytokine secretion patterns of NK cells and macrophages in early human pregnancy decidua and blood: implications for suppressor macrophages in decidua," American Journal of Reproductive Immunology, vol. 50, no. 6, pp. 444-452, 2003.

[31] D. J. Dudley, C. Hunter, M. D. Mitchell, and M. W. Varner, "Amniotic fluid interleukin-10 (IL-10) concentrations during pregnancy and with labor," Journal of Reproductive Immunology, vol. 33, no. 2, pp. 147-156, 1997.

[32] P. C. Greig, W. N. Herbert, B. L. Robinette, and L. A. Teot, "Amniotic fluid interleukin-10 concentrations increase through pregnancy and are elevated in patients with preterm labor associated with intrauterine infection," American Journal of Obstetrics and Gynecology, vol. 173, no. 4, pp. 1223-1227, 1995.

[33] E. S. Ginsburg, L. Xiao, A. R. Gargiulo et al., "Th2 and 3 type immunity to trophoblast in successful IVF-ET," Fertility and Sterility, vol. 83, no. 6, pp. 1659-1664, 2005.

[34] M. Y. Wu, H. F. Chen, S. U. Chen, K. H. Chao, Y. S. Yang, and H. N. Ho, "Increase in the production of interleukin-10 early after implantation is related to the success of pregnancy," 
American Journal of Reproductive Immunology, vol. 46, no. 6, pp. 386-392, 2001.

[35] N. Inagaki, C. Stern, J. McBain, A. Lopata, L. Kornman, and D. Wilkinson, "Analysis of intra-uterine cytokine concentration and matrix-metalloproteinase activity in women with recurrent failed embryo transfer," Human Reproduction, vol. 18, no. 3, pp. 608-615, 2003.

[36] J. A. Maybin, H. O. Critchley, and H. N. Jabbour, "Inflammatory pathways in endometrial disorders," Molecular and Cellular Endocrinology, vol. 335, pp. 42-51, 2011.

[37] S. D. Spandorler, A. Neuer, H. C. Liu et al., "Involvement of ILI and ILIRa in in vitro embryo development among wottien undergoing IVF-ET," Journal of Assisted Reproduction and Genetics, vol. 20, pp. 502-505, 2003.

[38] M. Araki, Y. Fukumatsu, H. Katabuchi, L. D. Shultz, K. Takahashi, and H. Okamura, "Follicular development and ovulation in macrophage colony-stimulating factor-deficient mice homozygous for the osteopetrosis (op) mutation," Biology of Reproduction, vol. 54, no. 2, pp. 478-484, 1996.

[39] P. F. Terranova and V. M. Rice, "Review: cytokine involvement in ovarian processes," American Journal of Reproductive Immunology, vol. 37, no. 1, pp. 50-63, 1997.

[40] C. M. Boomsma, A. Kavelaars, M. J. Eijkemans et al., "Endometrial secretion analysis identifies a cytokine profile predictive of pregnancy in IVF," Human Reproduction, vol. 24, no. 6, pp. 1427-1435, 2009. 


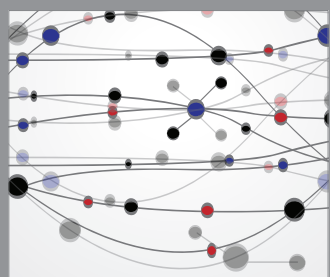

The Scientific World Journal
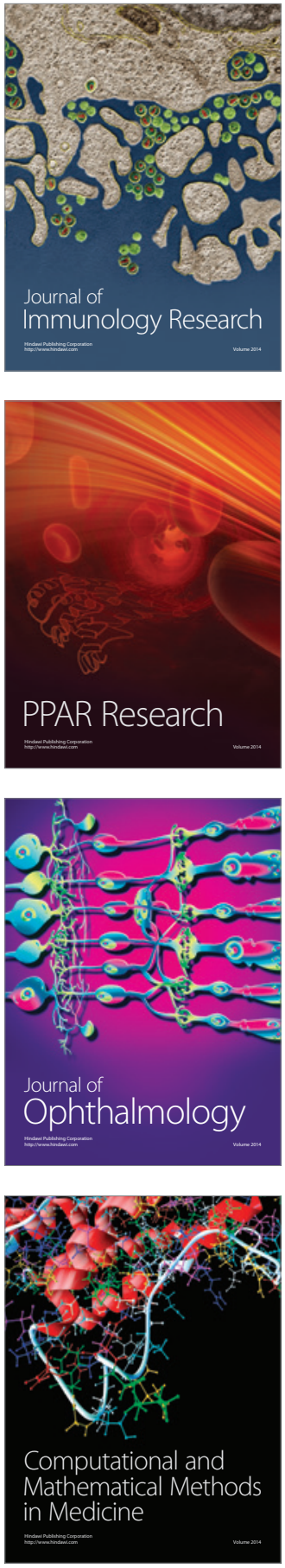

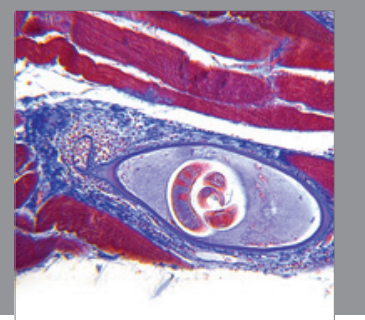

Gastroenterology

Research and Practice
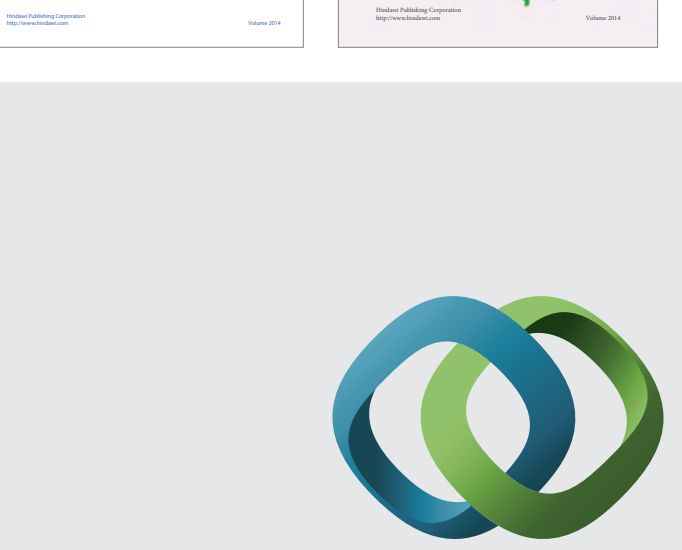

\section{Hindawi}

Submit your manuscripts at

http://www.hindawi.com
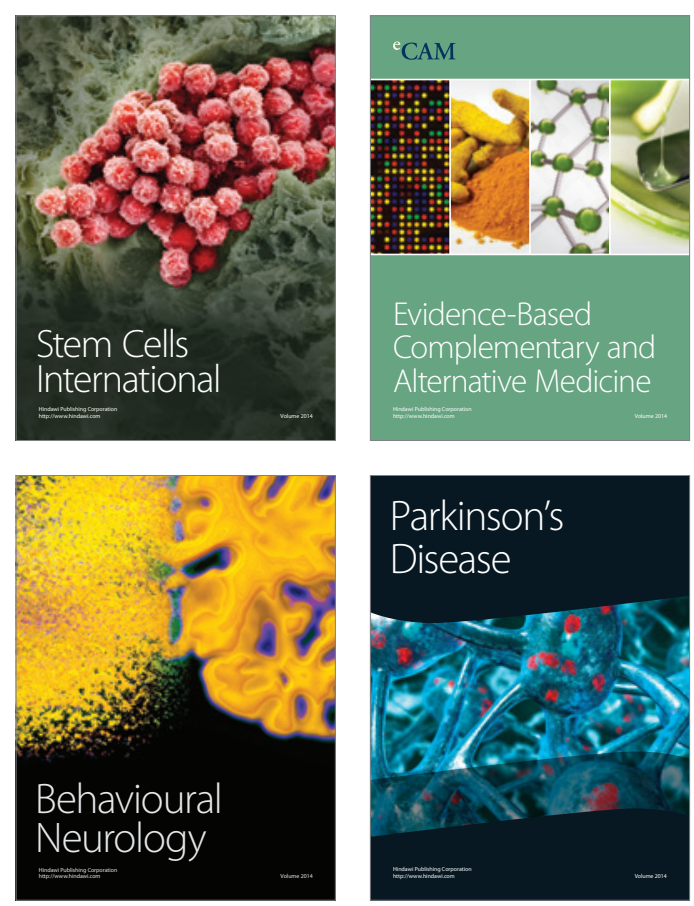

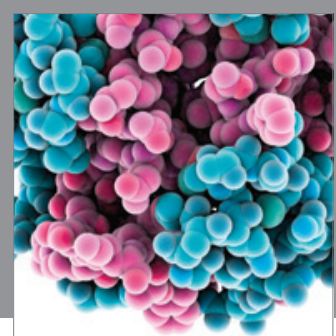

Journal of
Diabetes Research

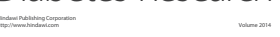

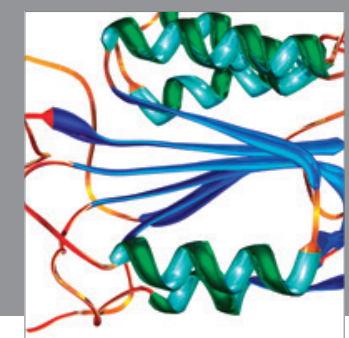

Disease Markers
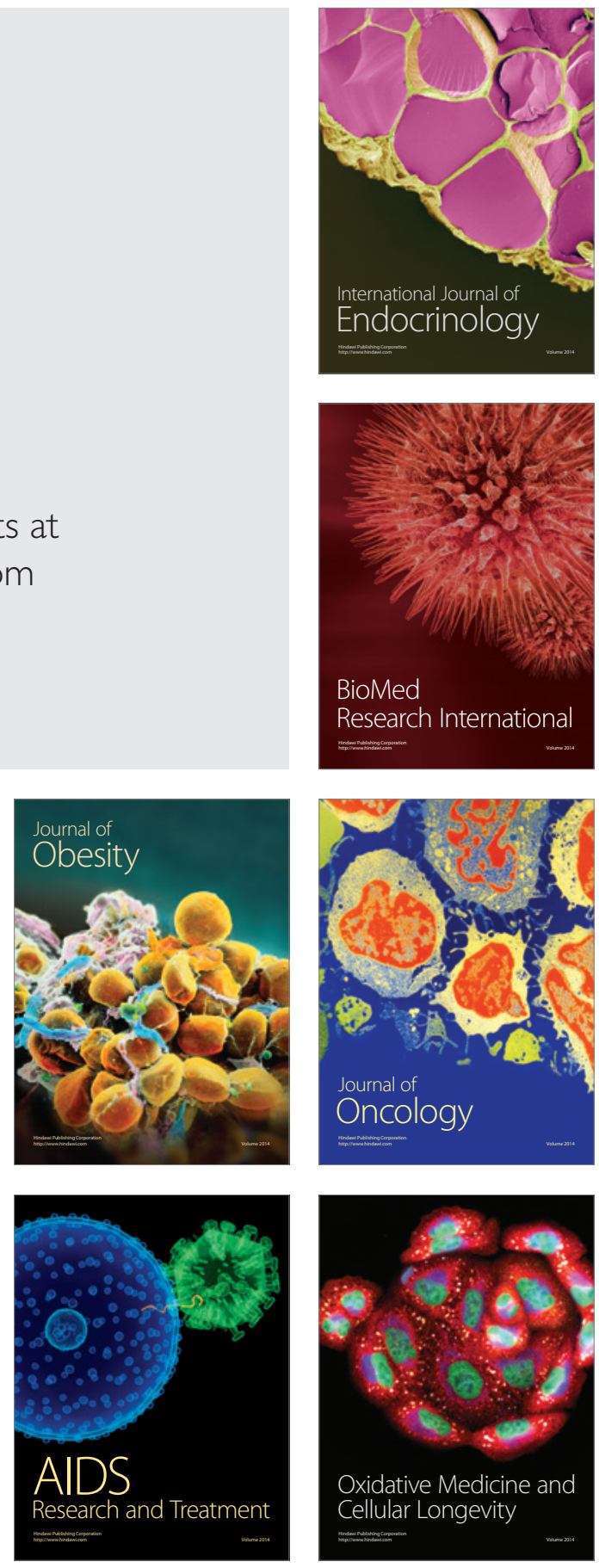